\title{
Swift BAT Loop Heat Pipe \#0 Temperature Droop Problem and Solution after Its Primary Heater Controller Failure
}

\author{
Michael K. Choi* \\ NASA Goddard Space Flight Center, Greenbelt, MD 20771
}

\begin{abstract}
The primary heater controller for Burst Alert Telescope (BAT) loop heat pipe (LHP) \#0 failed on March 31, 2010. It has been disabled. The secondary heater circuit is operational. However the set point tolerance of the secondary heater controller is significantly out of specifications. A novel variable conductance heat pipe (VCHP) is used to pre-condition the LHP propylene liquid before it returns to the compensation chamber (CC). Due to the limit on the quantity of power switches, the LHP and VCHP temperatures are controlled by different channels of the same heater controller. For this reason, the VCHP heater controller channel is also out of specification. It caused larger tolerances in the temperature of the propylene liquid returning to the $\mathrm{CC}$. As a result, there were intermittent temperature droops every 10-14 days at the coldest attitude during the eclipse. After the set point of the secondary heater controller was gradually increased from $8^{\circ} \mathrm{C}$ to $8.7^{\circ} \mathrm{C}$, there was no temperature droop for over four months.
\end{abstract}

\section{Nomenclature}

$\begin{array}{ll}\text { BAT } & =\text { Burst Alert Telescope } \\ \text { Block } & =\text { BAT detector array Block } \\ C C & =\text { compensation chamber } \\ C C H P & =\text { constant conductance heat pipe } \\ D A P & =\text { Detector Array Plate } \\ D M & =\text { Detector Module } \\ G R B & =\text { Gamma Ray Burst } \\ I \& T & =\text { integration and testing } \\ I P E & =\text { Image Processor Electronics } \\ L H P & =\text { loop heat pipe } \\ O B & =\text { optical bench } \\ P C B & =\text { Power Converter Box } \\ S / C & =\text { spacecraft } \\ T / B & =\text { thermal balance } \\ T / V & =\text { thermal vacuum } \\ U V O T & =\text { Ultraviolet Optical Telescope } \\ V C H P & =\text { variable conductance heat pipe } \\ X R T & =\text { X-ray Telescope }\end{array}$

\section{Introduction}

Swift is a National Aeronautics and Space Administration (NASA) Medium-Size Explorer (MIDEX) mission. The

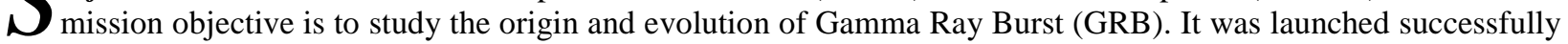
from Cape Canaveral Air Force Station, Florida into an orbit of 600-km altitude and $20.69^{\circ}$ inclination on November 20, 2004. Figure 1 shows the Swift observatory. The BAT Detector Array Blocks are thermally well coupled to eight constant conductance heat pipes (CCHPs) embedded in the detector array plate (DAP). Two LHPs (\#0 and \#1) transport heat from the CCHPs to a radiator, which is located on the shaded side of the observatory. They provide redundancy. The CCHPs have ammonia as the working fluid and the LHPs have propylene as the working fluid. Figure 2 shows the LHP thermal system. ${ }^{1}$

\footnotetext{
* Senior Thermal Engineer, Thermal Engineering Branch/Code 545, AIAA Associate Fellow.
} 


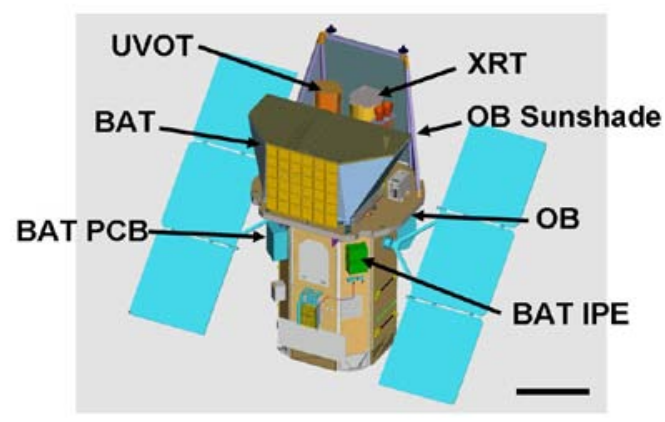

Figure 1. Swift Observatory (View from Shaded Side).

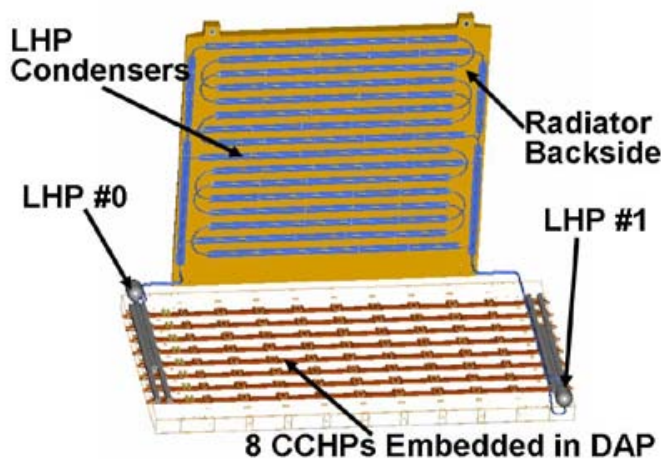

Figure 2. BAT LHP Thermal System.

The Swift observatory is required to slew to targets within $50^{\circ}$ in 75 seconds, and to targets from $50^{\circ}$ to $270^{\circ}$ in 75 to 270 seconds. The allowable sun angle, which is the angle between the optical axis (+X axis) and solar vector, is in the $45^{\circ}$ to $180^{\circ}$ range. The reason is that if the sun angle is less than $45^{\circ}$, direct sunlight enters the $\mathrm{x}$-ray Telescope (XRT) and Ultraviolet Optical Telescope (UVOT) through the apertures. The spacecraft is also allowed to rotate up to $\pm 10^{\circ}$ about the $+X$ axis. This limit on the roll angle prevents direct sunlight from reaching the BAT LHPs. Because of frequent slewing, the thermal environment for the Swift observatory changes constantly. Another factor that also affects the Swift thermal environment is the beta ( $ß)$ angle, which is in the $-44.14^{\circ}$ to $+44.14^{\circ}$ range, and changes at about $2^{\circ}$ per day (Figure 3). Direct sunlight is not permitted on the shaded side of the observatory because cold biased radiators for the nickel-hydrogen batteries, BAT Detector Array and XRT focal plane camera assembly heat rejection system are located there.,

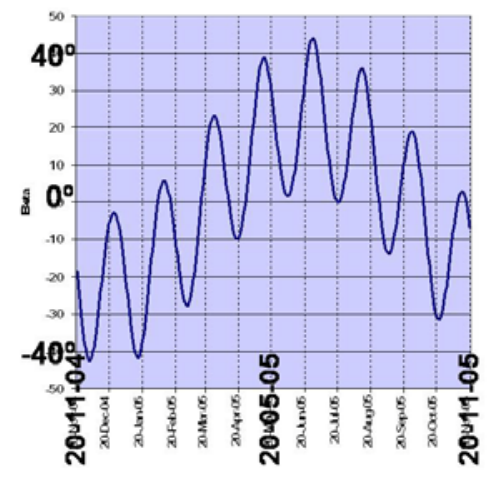

Figure 3. Swift Beta Angle ( ${ }^{\circ}$ ). 


\section{Objective}

The objective of this paper is to present the BAT LHP \#0 temperature droop problem after its primary heater controller failed on March 31, 2010 and its solution.

\section{Novel VCHP Feature for BAT LHP}

A novel feature of the BAT LHP is VCHP. The VCHP evaporator is thermally coupled to the LHP evaporator. A heat exchanger is swaged over the VCHP condenser to allow heat exchange between the VCHP condenser and LHP liquid return line (Figure 4). The CCHPs embedded in the DAP transfer heat from the Blocks (208 W) to the LHP evaporator. A small fraction of this heat transfers from the LHP evaporator to the VCHP evaporator. It provides preconditioning of the propylene liquid before it returns to the LHP CC. The VCHP was intended to reduce heater power to meet the budget. ${ }^{2,3,4}$

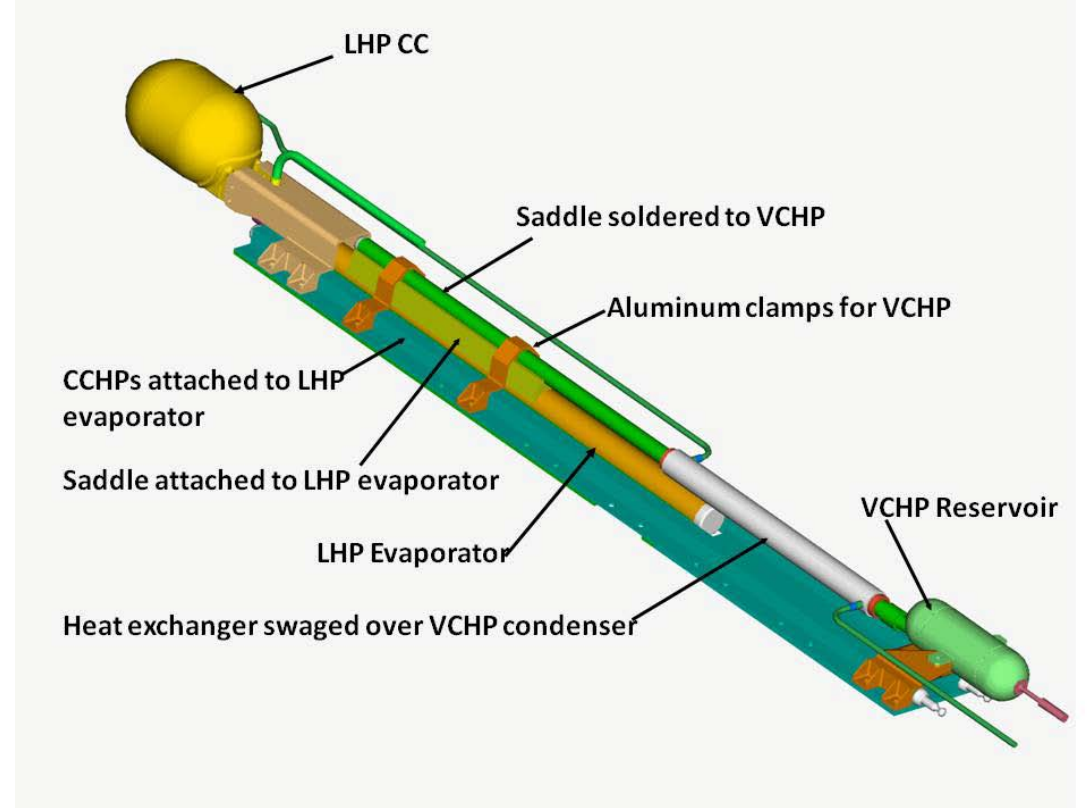

Figure 4. BAT LHP with Novel VCHP.

The BAT LHP CCs require heater controllers with adjustable set points in flight. As part of the LHP thermal system, the VCHP reservoirs also require a heater controller with adjustable set points in flight. In the operational mode, the set point of the VCHP reservoir heater controller is required to be $5^{\circ} \mathrm{C}$ colder than the LHP CC heater controller set point when the CC set point is $5^{\circ} \mathrm{C}$. For colder set points, a larger offset is required, and for warmer set points a smaller offset is required (Figure 5). Also the VCHP heater controller is required to work "in reverse" (i.e., off when the VCHP thermistor temperature feedback to the controller is below the set point, and on when it is above the set point). ${ }^{5}$ The VCHP thermistor is located at the LHP liquid return line just after it exits the heat exchanger (Figure 6). If the VCHP reservoir thermistor feedback to the controller is larger than the VCHP heater controller set point, the reservoir heater is powered on and the non-condensable gas expands. This reduces the VCHP condenser area and decreases the heat transfer from the VCHP to the LHP liquid return line. The BAT Power Converter Box (PCB) supplies power and adjustable set point signals to the heater controllers. Due to the limit on the quantity of power switches, the LHP CC and VCHP reservoir temperatures are required to be controlled by the same heater controller. To make it possible, a heater controller with three control units or channels was developed for the BAT LHPs. One of the channels is used for temperature control of the VCHP reservoir (Figure 7). The offset and workin-reverse capabilities were integrated into the heater controller. 


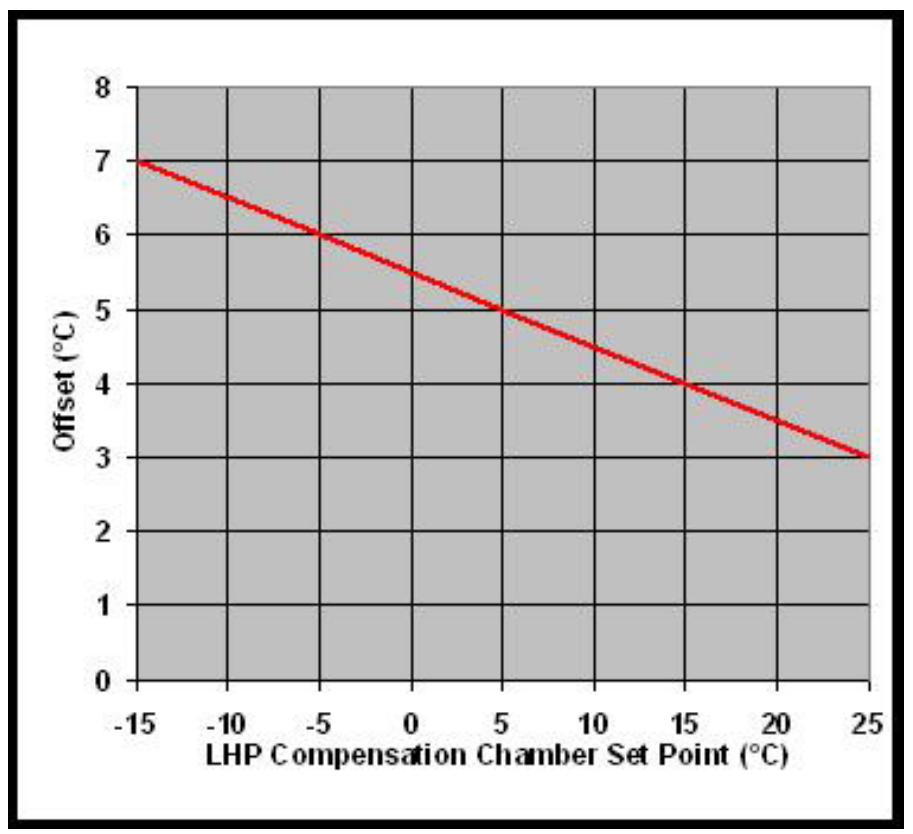

Figure 5. Offset for VCHP.
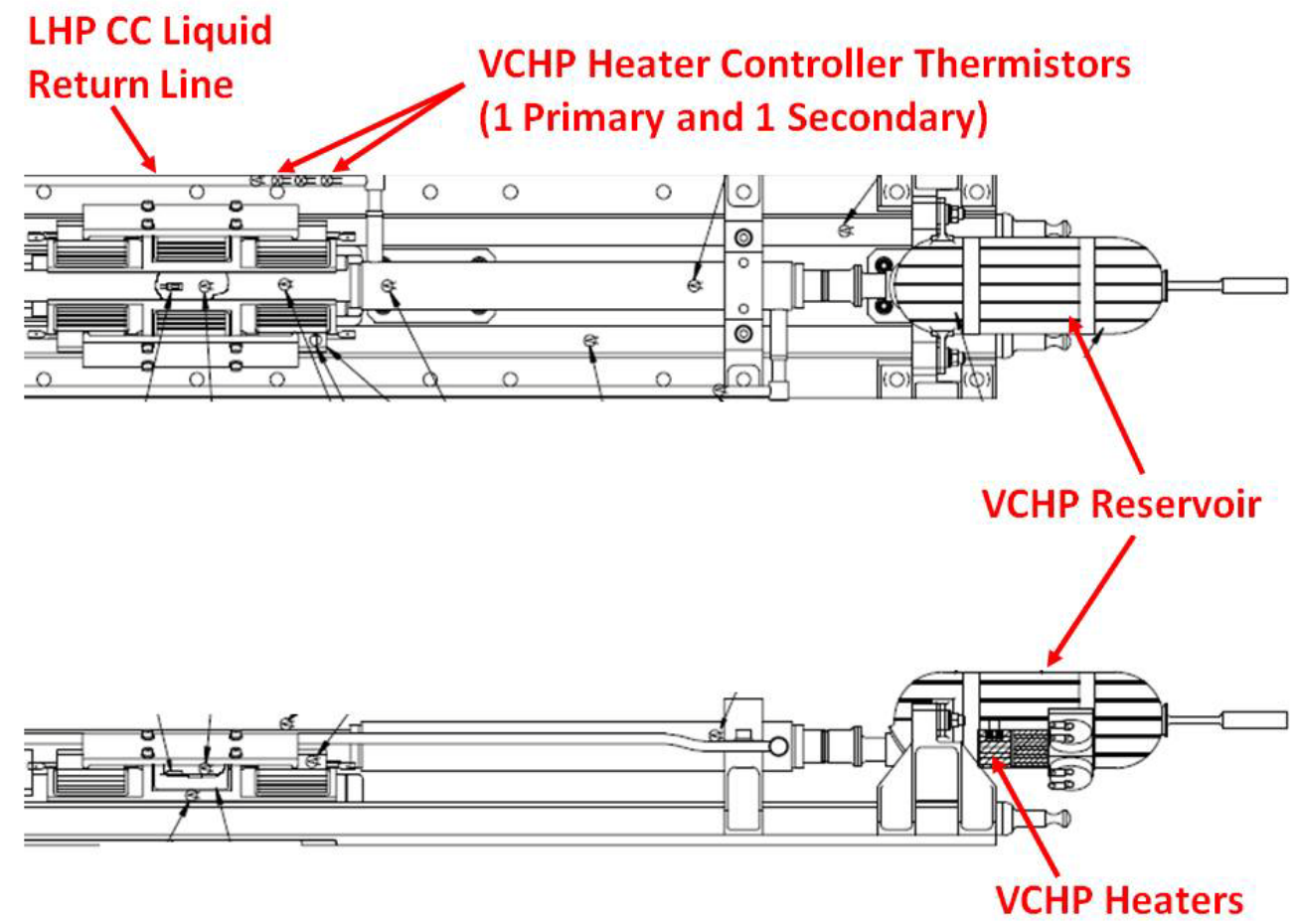

Figure 6. VCHP Heater and Heater Controller Thermistor Locations. 


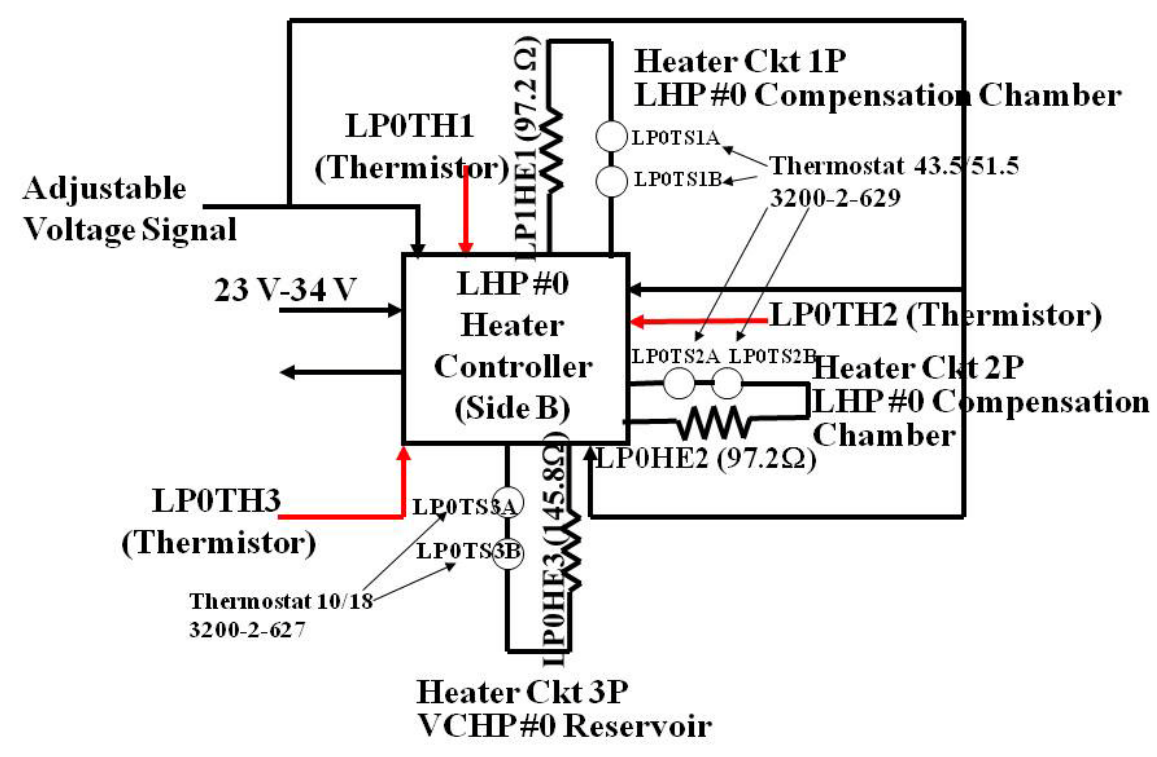

Figure 7. LHP and VCHP Heater Controller.

\section{Temperature Droops after LHP \#0 Primary Heater Controller Failure}

On March 31 (Day 90), 2010, the primary heater controller of LHP \#0 failed. The LHP \#0 CC temperature decreased rapidly and activated the secondary heater controller circuit. Note that the primary heater controller is Side A and the secondary heater controller is Side B of the same board (Figure 8). ${ }^{5}$ The set point of the secondary heater controller was $6^{\circ} \mathrm{C}$, which was $2^{\circ} \mathrm{C}$ lower than that of the primary heater controller. After the secondary heater circuit was activated, LHP \#0 had temperature instability and a temperature droop every orbit (Figure 9). The temperature instability was caused by cold shock and much lower heater controller set point than that of LHP \#1. It led to temperature instability on LHP \#1 (Figure 10).

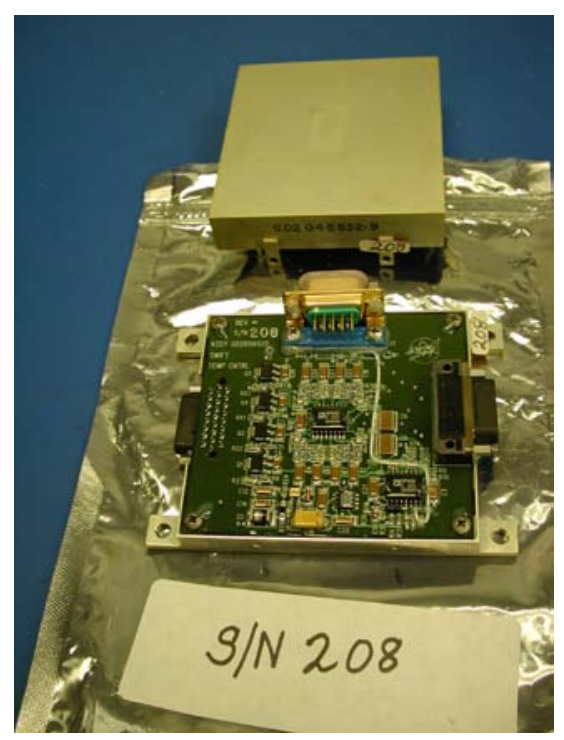

Figure 8. Heater Controller Board. 


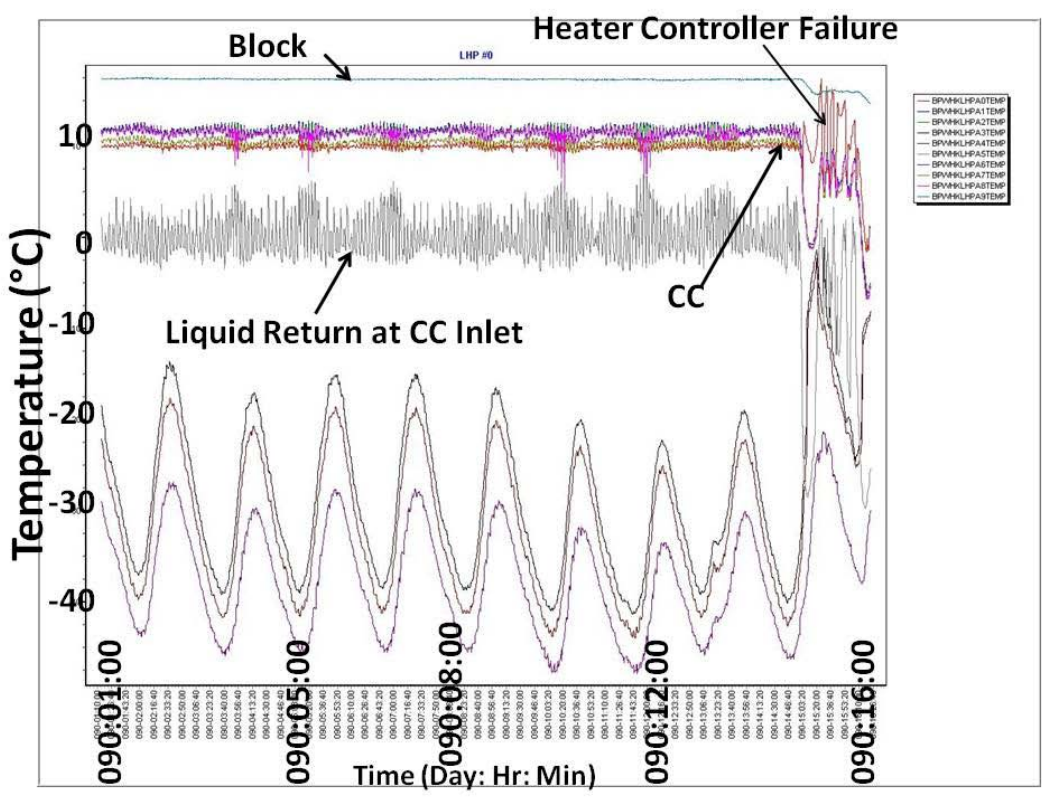

Figure 9. LHP \#0 and Block Temperatures on Day 90 (March 31), 2010.

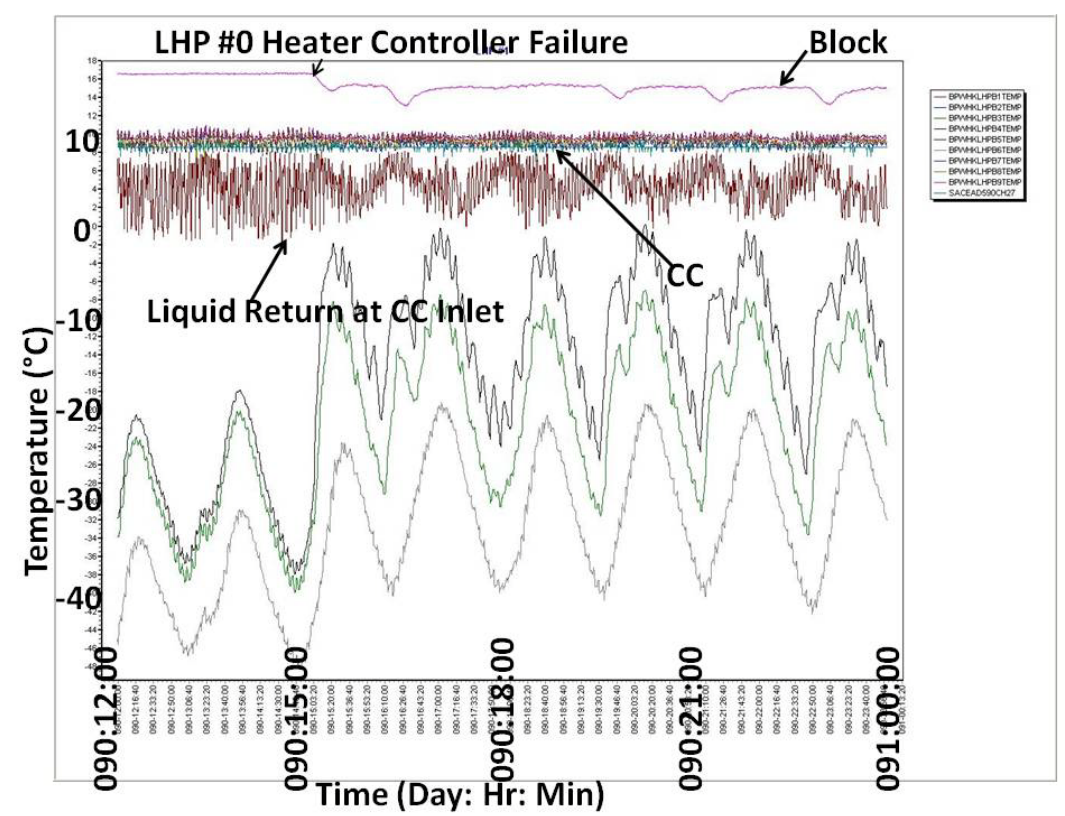

Figure 10. LHP \#1 and Block Temperatures on Day 90 (March 31), 2010.

On April 3, 2010, the LHP \#0 primary heater controller was disabled and the set point of LHP \#0 secondary heat controller was increased from $6^{\circ} \mathrm{C}$ to $8^{\circ} \mathrm{C}$. From the CC temperature in Figure 11, the secondary heater controller had a significantly larger tolerance than that of the primary heater controller in Figure 8. The AD590 temperature sensor for housekeeping telemetry and the thermistor for feedback to the heater controller are both adjacent to the heater (Figure 12). Secondly the temperature of the liquid return at the CC inlet had a wider range than that before the primary heater controller failed. Thirdly the Block temperature was colder than before the heater controller failure. On April 6, a temperature droop occurred. It recovered in one orbit (Figure 13). Also telemetry BPWHKLHPA5TEMP violated the alarm low limit. This temperature sensor measures the temperature of propylene liquid at the LHP CC inlet, where liquid returns to the CC from the VCHP heat exchanger (Figures 14 and 15). 


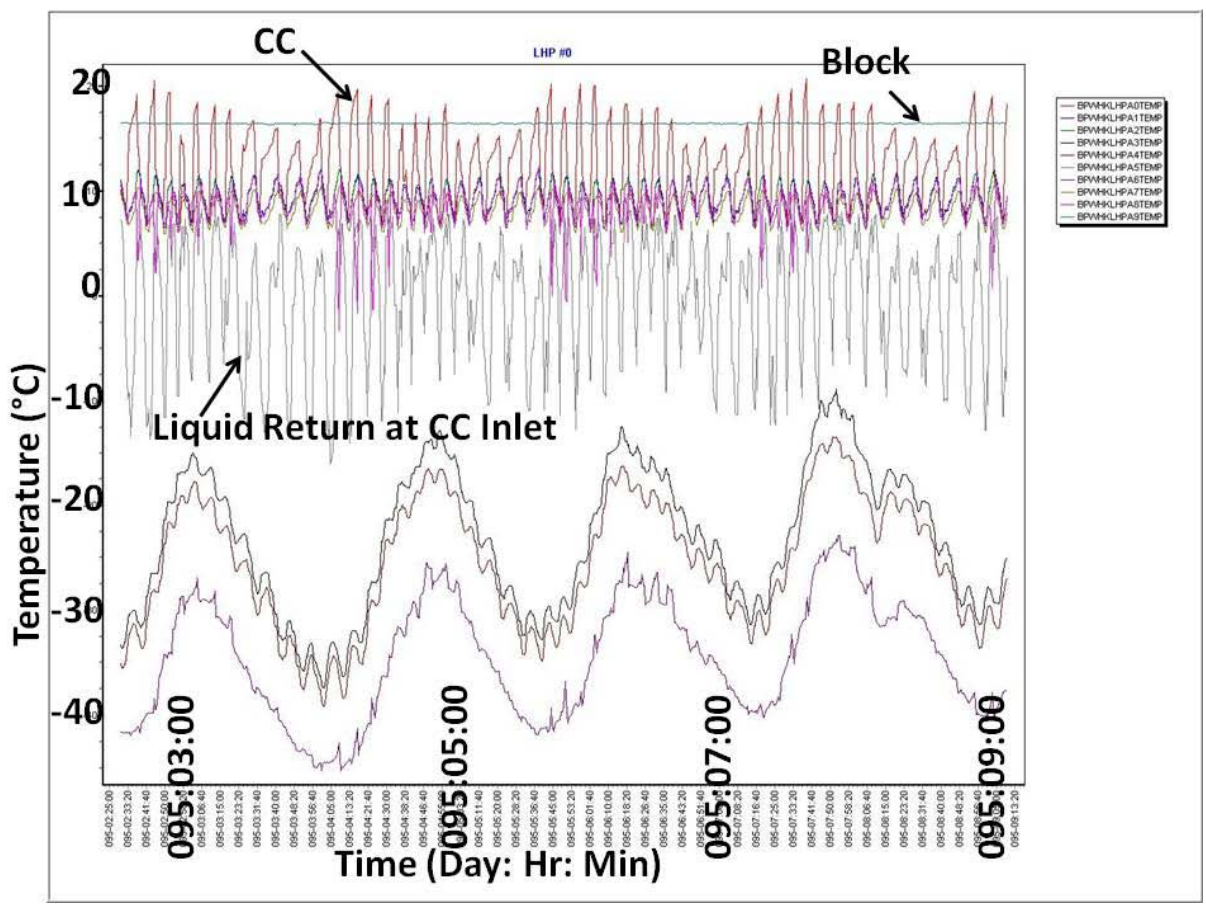

Figure 11. LHP \#0 and Block Temperatures on Day 95 (April 5), 2010.
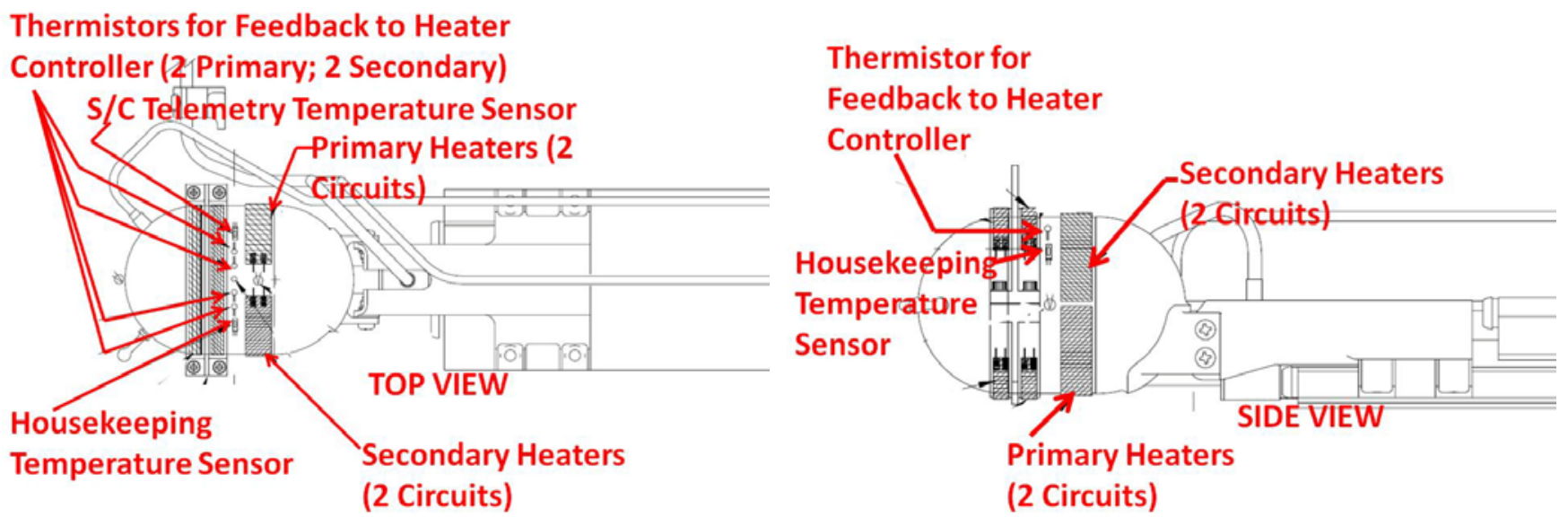

Figure 12. CC Temperature Sensor and Heater Locations. 


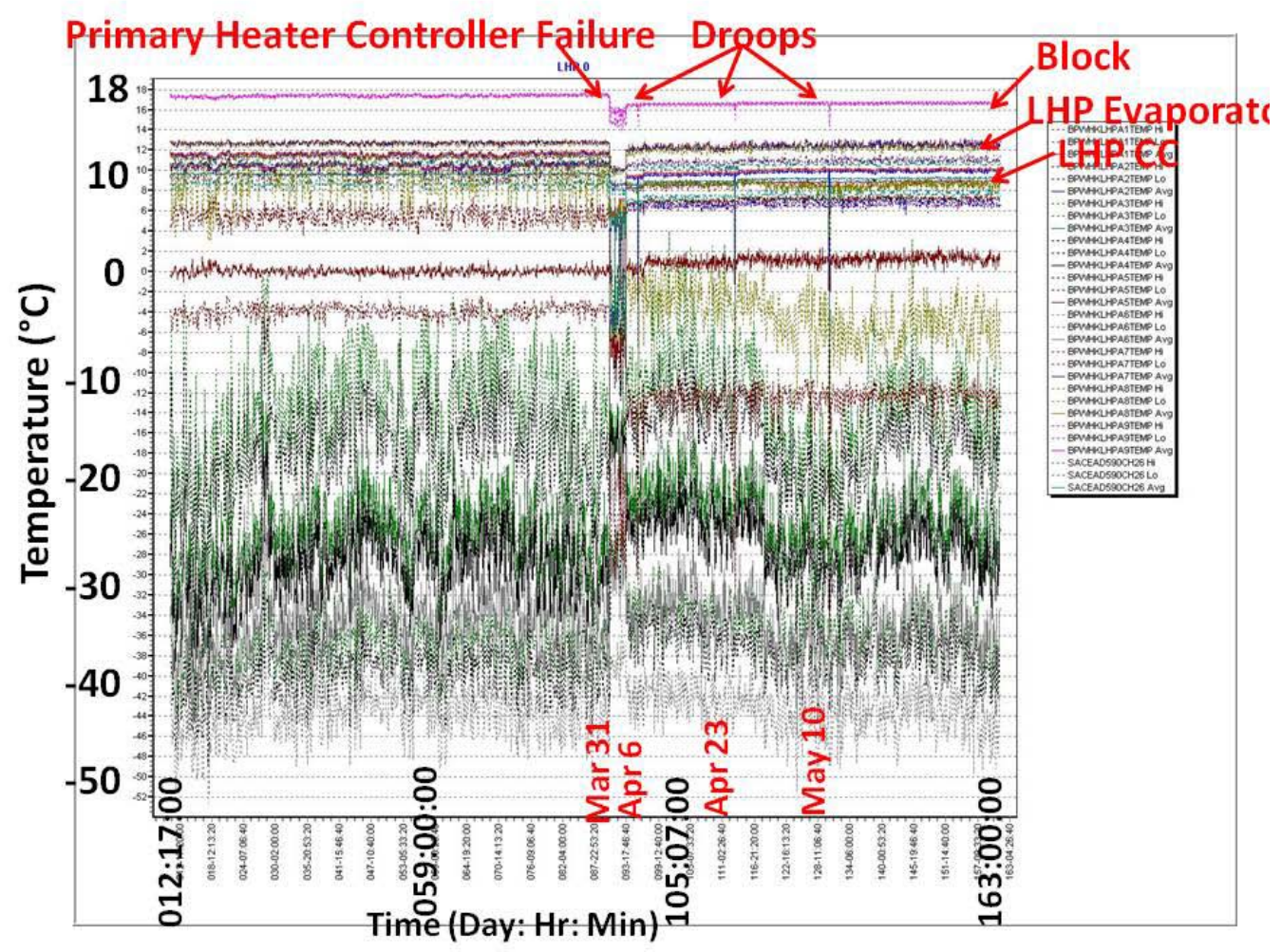

Figure 13. Temperature Droop.

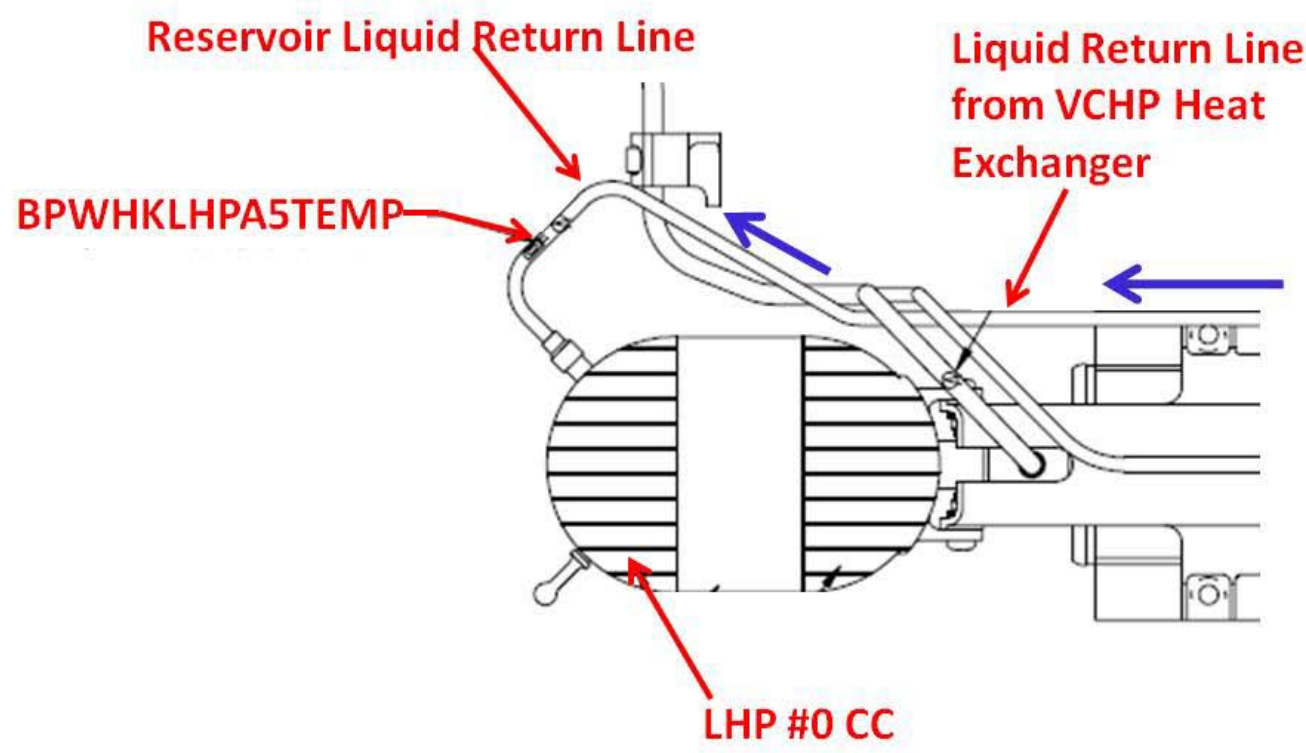

Figure 14. LHP Liquid Return at CC Inlet. 


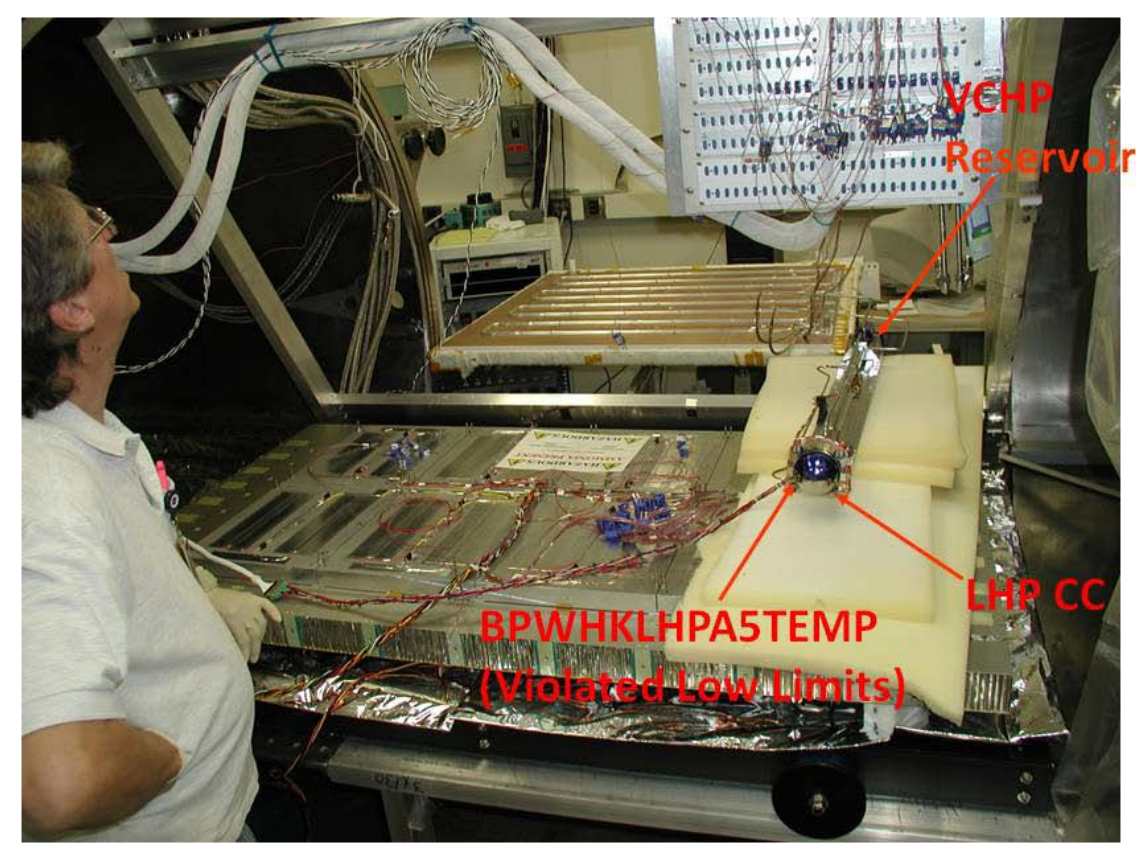

Figure 15. LHP Liquid Return at CC Inlet Telemetry Location.

It appears that the LHP \#0 secondary heater controller set point tolerance was out of specifications. The tolerance in the specifications is no larger than $\pm 0.25^{\circ} \mathrm{C} .{ }^{6}$ Because the heater controller tolerance far exceeded the specification, it had the following consequence. At the coldest attitude and in the eclipse when the temperature of the liquid return from the VCHP heat exchanger to the CC was not sufficiently pre-conditioned, a temperature droop occurred. If the VCHP heater controller is a separate controller (i.e., not a channel of the LHP heater controller), the temperature of the liquid return from the VCHP heat exchanger to the CC could be controlled adequately to prevent a temperature droop. On April 6, 2010, the set point of LHP \#0 secondary heat controller was increased to $8.25^{\circ} \mathrm{C}$.

On April 23, 2010, another temperature droop occurred (Figure 13). Also telemetry BPWHKLHPA5TEMP violated the alarm low limit. The temperature droop recovered in one orbit. For the same reason as the first temperature droop, the set point of LHP \#0 secondary heat controller was increased from $8.25^{\circ} \mathrm{C}$ to $8.5^{\circ} \mathrm{C}$. Afterward the liquid return at CC inlet temperature still had a significantly wider range than that before the March 31 primary heater controller failure (Figure 16). Also the Block temperature was still slightly colder than that before the March 31 primary heater controller failure. Figure 17 displays the temperature range of telemetry BPWHKLHPA5TEMP before and after the primary heater controller failure. It can be seen that it is about $13^{\circ} \mathrm{C}$ wider after the primary heater controller failure. 


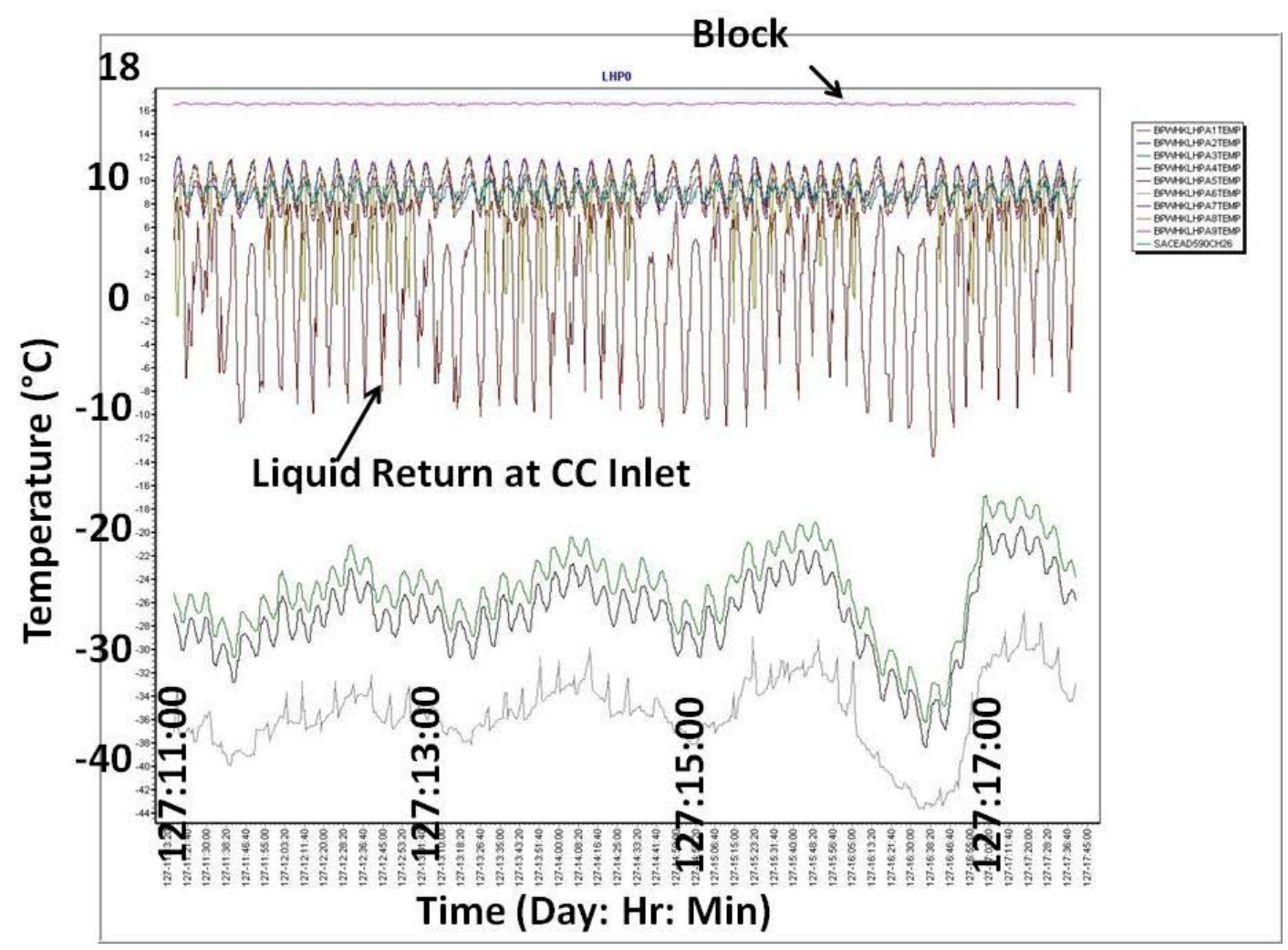

Figure 16. LHP \#0 and Block Temperatures on Day 127, 2010.

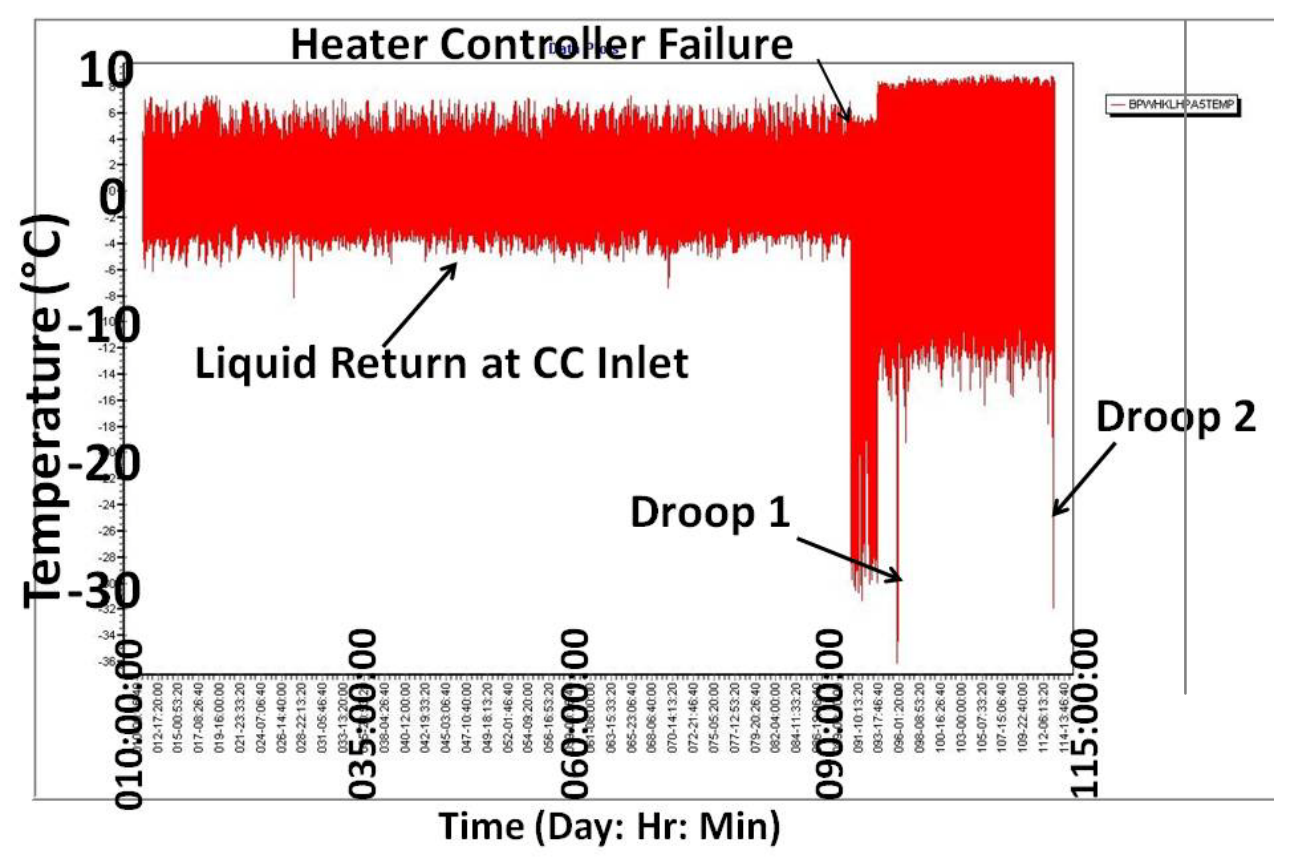

Figure 17. Temperature Range of BPWHKLHPA5TEMP. 
On May 10, another temperature droop occurred (Figure 11) and BPWHKLHPA5TEMP violated the alarm low limit again. For each temperature droop, the detector module Block XA1 temperature dropped about $1.5^{\circ} \mathrm{C}$, which had no obvious impact on the BAT count rates or detecting GRB. It appears that intermittent temperature droops, once every 10-14 days, occurred at the coldest attitude and during the eclipse.

During the BAT integration and testing (I\&T), the BPWHKLHPA5TEMP low alarm limits were set to $-25^{\circ} \mathrm{C}$ for yellow and $-30^{\circ} \mathrm{C}$ for red. These limits were intended to alarm non-nominal LHP operation. A thermocouple (TC35), adjacent to BPWHKLHPA5TEMP, was used in BAT instrument level thermal balance (T/B) and thermal vacuum (T/V) cycling tests. Also a thermocouple (TC34) was used to monitor temperature of liquid line outlet of VCHP heat exchanger. The test results show that TC34 and TC35 temperatures are nearly the same and the coldest temperature of TC34 or TC35 in tests is $-70^{\circ} \mathrm{C}$ (Figure 18). On May 17, 2010, the BPWHKLHPA5TEMP alarm low limits for flight operation were changed to $-35^{\circ} \mathrm{C}$ yellow and $-40^{\circ} \mathrm{C}$ red. This change was intended to prevent alarms caused by temperature droop.

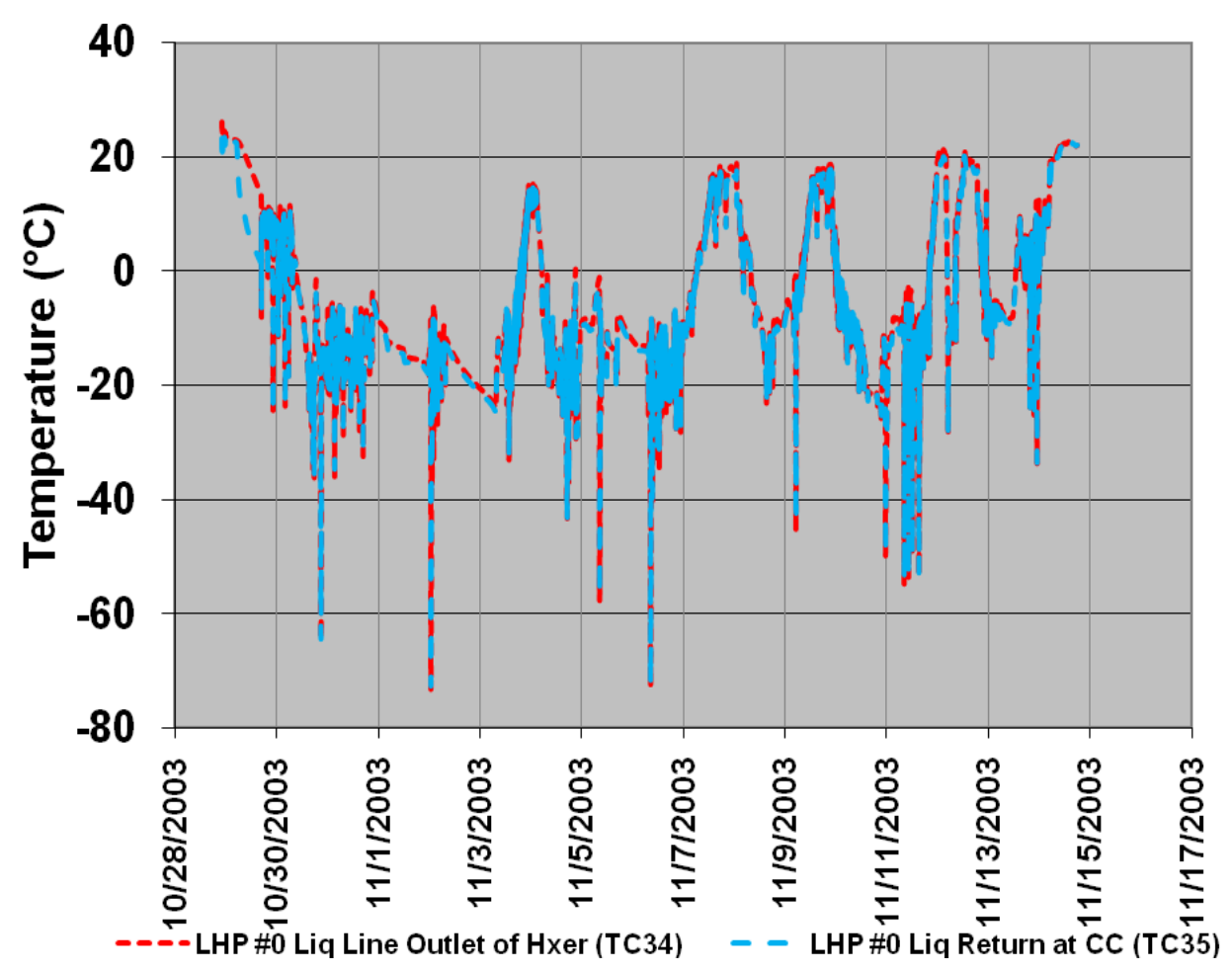

Figure 18. LHP \#0 Liquid Return at CC Inlet Temperature in BAT T/V Test.

On May 18, 2010, the set point of the LHP \#0 secondary heat controller was increased from $8.5^{\circ} \mathrm{C}$ to $8.6^{\circ} \mathrm{C}$. Afterward, there was no temperature droop between May 18 and June 11. The LHP \#0 evaporator temperature was still about $0.1^{\circ} \mathrm{C}$ colder than that before the March 31 primary heater controller failure. Therefore on June 11, the LHP \#0 secondary heater controller set point was increased to $8.7^{\circ} \mathrm{C}$ to enhance the VCHP heater control and to raise its evaporator temperature to that before primary heater controller failure. There was no temperature droop for more than 4 months (Figure 19). 


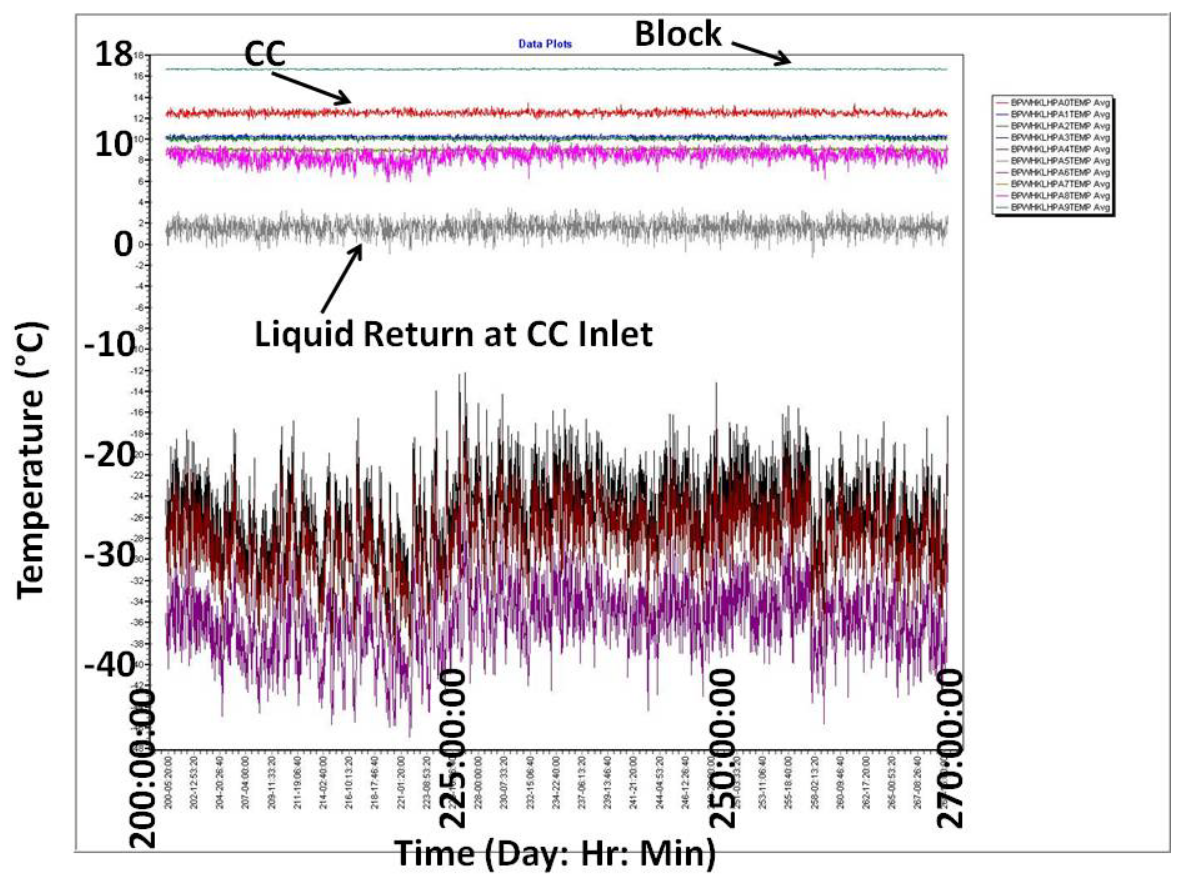

Figure 19. LHP \#0 and Block Temperatures from Day 200-285, 2010.

As of April 4, 2011, LHP \#0 is still operating and the BAT continues detecting GRB. Figure 20 shows the temperatures of the LHP \#0 from January 28-April 1, 2011. There was no temperature droop during that 62-day period.

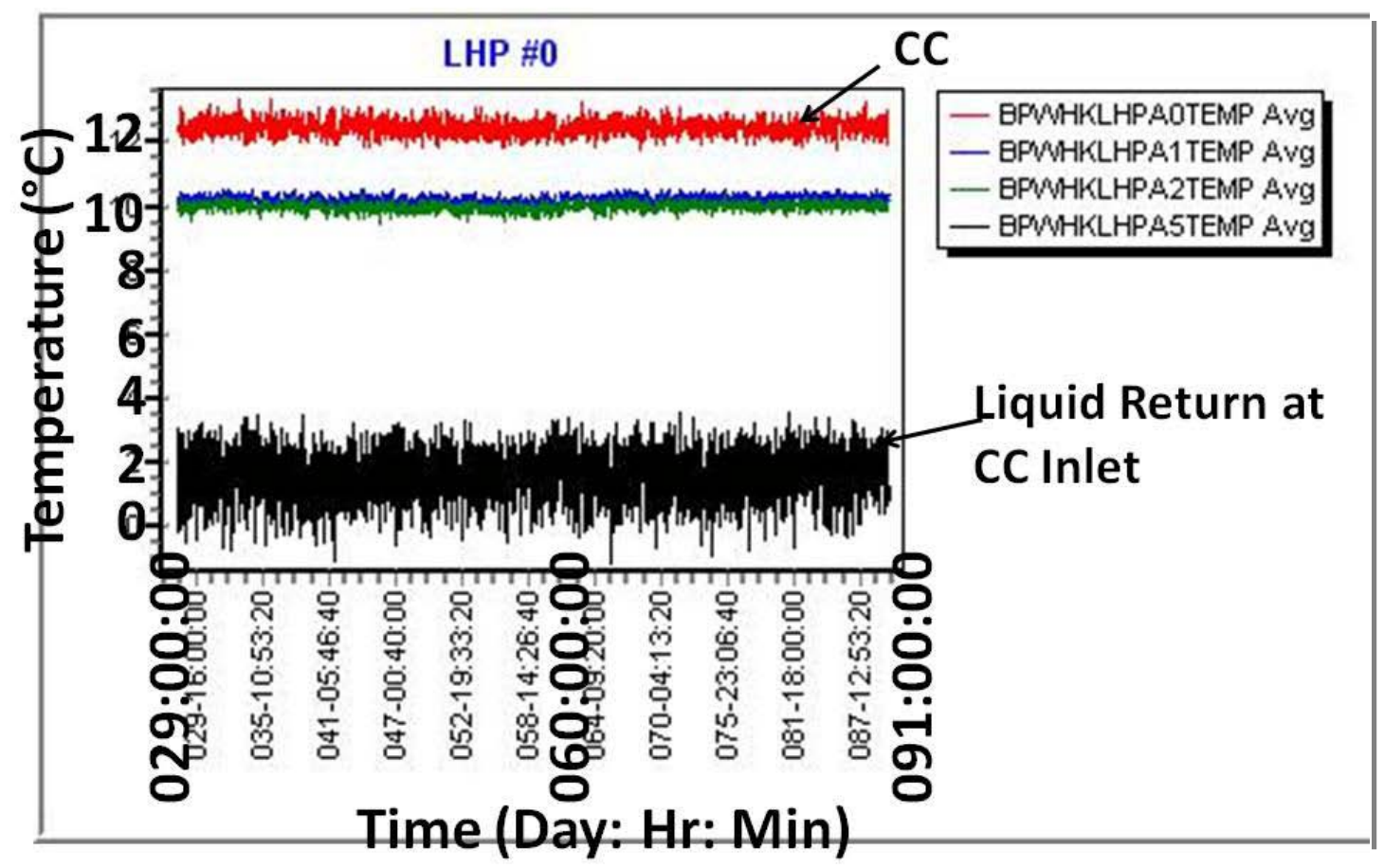

Figure 20. LHP \#0 Temperature from Day 28-91, 2011. 


\section{Conclusion}

The Swift BAT thermal control system is robust, including redundancy of LHPs, CCHPs, heater circuits, and heater controllers. The primary heater controller for LHP \#0 failed on March 31, 2010. It has been disabled. The secondary heater circuit is operational. However the set point tolerance of the secondary heater controller is significantly out of specifications. It appears that the secondary heater controller had degraded from launch through March 31, 2010. A novel VCHP feature is used on the BAT LHP. It pre-conditions the LHP propylene liquid before it returns to the CC. It reduces heater power to meet the budget. The VCHP reservoir heater controller requires a set point offset from the LHP heater controller and to work "in reverse". Due to the limit on the quantity of power switches, the LHP CC and VCHP reservoir temperatures are controlled by the same heater controller. To make it possible, one of the channels of each heater controller for the LHP CCs is used for temperature control of the VCHP reservoir. Because the LHP \#0 secondary heater controller set point tolerance is out of specifications, the VCHP heater controller channel is also out of specifications. It caused larger tolerances in the temperature of the propylene liquid returning to the CC. As a result, there were intermittent temperature droops every 10-14 days. They recovered in one orbit. Insufficient pre-conditioning by the VCHP at the coldest attitude and during the eclipse caused these droops. Telemetry BPWHKLHPA5TEMP violated the alarm yellow limit of $-25^{\circ} \mathrm{C}$. To prevent the alarms in flight operation, the yellow limit was relaxed to $-35^{\circ} \mathrm{C}$ because it was tested to $-70^{\circ} \mathrm{C}$ in the BAT T/V test. After the set point of the secondary heater controller was increased from $8^{\circ} \mathrm{C}$ to $8.7^{\circ} \mathrm{C}$ in four steps, there was no temperature droop for over four months. As of April 4, 2011, LHP \#0 is still operating. The novel VCHP feature for reducing LHP CC heater power has now been flight proven and is highly recommended. The type of LHP heater controller complexity is not recommended for instrument or spacecraft thermal control. Separate heater controllers for LHP and VCHP are recommended. Redundancy in heater circuits, including heater controllers, temperature sensors and heaters, is highly recommended for spacecraft or instrument thermal control. It should be on the selected redundancy list even redundancy is not required at the mission level.

\section{References}

${ }^{1}$ Choi, M. K., "Swift BAT Loop Heat Pipe Thermal System Characteristics and Ground/ Flight Operation Procedure", $1^{\text {st }}$ Int'l Energy Conversion Engineering Conf. Proceedings, Portsmouth, VA, 17-21 Aug., 2003, Paper No. AIAA-2003-6077.

${ }^{2}$ Choi, M. K., “Thermal Assessment of Swift BAT Instrument Thermal Control System in Flight,” SAE 35 ${ }^{\text {th }}$ Int'l Conference on Environmental Systems, 11-14 Jul., 2005, Rome, Italy, SAE Paper 2005-01-3037.

${ }^{3}$ Choi, M. K., “Thermal Assessment of Swift Instrument Module Thermal Control System during First 2.5 Years in Flight," SAE 37 ${ }^{\text {th }}$ Int'l Conference on Environmental Systems, 9-12 Jul., 2007, Chicago, IL, SAE Paper 2007-01-3083.

${ }^{4}$ Choi, M. K., "Thermal Assessment of Swift Instrument Module Thermal Control System and Mini Heater Controllers After 5+ Years in Flight,” AIAA 40 ${ }^{\text {th }}$ Int'l Conference on Environmental Systems,11-15 Jul., 2010, Barcelona, Spain, Paper No. AIAA-2010-6003.

${ }^{5}$ Choi, M. K., "Thermal Evaluation of NASA/Goddard Heater Controllers on Swift BAT, Optical Bench and ACS", $3^{\text {rd }}$ Int’l Energy Conversion Engineering Conf. Proceedings, San Francisco, CA, 15-18 Aug., 2005, Paper No. AIAA-2005-5607.

${ }^{6}$ Bloom, D. D., "Swift Burst Alert Telescope (BAT) Temperature Controller Specification”, 410.4-SPEC-0014, NASA GSFC, Sept., 2001. 